\title{
RANCANGAN PEMBELAJARAN SIMULASI DAN KOMUNIKASI DIGITAL (SIMKOMDIG) KELAS X SMK GUNA JAYA KABUPATEN INDRAGIRI HILIR, RIAU
}

\author{
Penulis \\ : Abdurrahman Saleh \\ Institusi \\ : Magister Teknologi Pendidikan Universitas Muhammadiyah Jakarta \\ Email Korespondensi : abdurrahmansaleh5669@gmail.com \\ DOI \\ : https://doi.org/10.53947/perspekt.v1i1.3
}

Kata Kunci:

Desain Pembelajaran Bahan Pembelajaran. Panduan Evaluasi Model Pembelajaran Dick \& Carrey

Keywords:

Learning Design

Learning Materials.

Evaluation Guide

Dick and Carey learning model

\begin{abstract}
Abstrak
Rancangan pembelajaran simulasi dan komunikasi digital kelas sepuluh di Sekolah Menengah Kejuruan (SMK) Guna Jaya Kecamatan Keritang, Kabupaten Indragiri Hilir, Riau, disusun berdasarkan model pembelajaran Dick dan Carey. Terdiri dari sepuluh tahapan perancangan, yaitu (1) melakukan identifikasi tujuan pembelajaran; (2) melakukan analisis intruksional; (3) menganalisis karakteristik siswa dan konteks pembelajaran; (4) merumuskan tujuan pembelajaran khusus; (5) mengembangkan instrumen penilaian; (6) mengembangkan strategi pembelajaran; (7) mengembangkan dan memilih bahan pembelajaran; (8) merancang dan mengembangkan evaluasi formatif; (9) melakukan revisi terhadap program pembelajaran; (10) merancang dan mengembangkan evaluasi sumatif. Hasil rancangan berupa (a) panduan pembelajaran (b) rencana pembelajaran (c) penilaian, dan (d) evaluasi pembelajaran dalam bentuk kompilasi dari bab-bab dan Kompetensi Dasar (KD) dalam buku Simulasi dan Komunikasi Digital Kelas X SMK.
\end{abstract}

\begin{abstract}
The tenth-grade digital communication and simulation learning design at Guna Jaya Vocational High School (SMK) Guna Jaya, Keritang District, Indragiri Hilir Regency, Riau, was compiled based on the Dick and Carey learning model. It consists of ten stages of design, namely (1) identifying learning objectives; (2) perform instructional analysis; (3) analyzing student characteristics and learning contexts; (4) formulating specific learning objectives; (5) developing assessment instruments; (6) developing learning strategies; (7) developing and selecting learning materials; (8) designing and developing formative evaluations; (9) revise the learning program; (10) design and develop a summative evaluation. The results of the design are (a) learning guide, (b) lesson plan, (c) assessment,
\end{abstract}

\section{PENDAHULUAN}

Salah satu komponen penting dalam memulai proses pembelajaran adalah kesiapan guru dalam mendesain pembelajaran dan menerapkan rencana pembelajaran agar tujuan pembelajaran dapat tercapai. Komponen dan tahapan model Dick and 
Carey lebih kompleks jika dibandingkan dengan model pembelajaran yang lain, seperti Morrison, Ross, \& Kemp (2001). Walaupun model Morrison, Ross, \& Kemp juga memandang desain pembelajaran sebagai sebuah sistem, tetapi sedikit berbeda. Mereka menyebutkan desain pembelajaran sebagai metode yang sistematis tetapi bukan pendekatan sitematis. Tahapan yang digunakan yaitu perencanaan, pengembangan, evaluasi, dan manajemen proses. Guru yang baik adalah guru yang selalu berusaha untuk menciptakan pembelajaran yang terbaik. Untuk menciptakan pembelajaran yang terbaik, seorang guru harus pandai-pandai mendesain model pembelajaran. Model Dick dan Carrey memiliki 10 langkah pembelajaran yang sistematis, dari mengidentifikasi tujuan umum pembelajaran sampai melaksanakan evaluasi.

Mata pelajaran Simulasi dan Komunikasi Digital (SIMKOMDIG) Kelas X SMK termasuk dalam kategori mata pelajaran yang baru dikembangkan untuk memenuhi kebutuhan kurikulum SMK prodi Informasi dan Teknologi (IT). Perancangan pembelajaran mata pelajaran tersebut dengan menggunakan model Dick and Carey ini diharapkan dapat memberi kontribusi tersedianya sistem pembelajaran yang berdasar pada kebutuhan siswa, lebih efisien dan efektif.

\section{KAJIAN LITERATUR}

\section{MODEL DESAIN SISTEM PEMBELA- JARAN DICK DAN CAREY}

Model desain sistem pembelajaran The Systematic Design of Instructional dikemukakan oleh Dick and Carey (2009) menggunakan pendekatan sistem atau system approach untuk mendesain sebuah program pembelajaran. Pendekatan tersebut meliputi analisis, desain, pengembangan, implementasi, dan evaluasi. Model ini terdiri dari beberapa komponen dan subkomponen yang perlu dilakukan secara sistematis dan sistemis untuk membuat rancangan aktifitas pembelajaran yang lebih besar. Suradika dkk (2020) menyatakan bahwa Model Dick dan Carey dipandang sebagai model desain pembelajaran yang dapat digunakan untuk merancang sistem pembelajaran pada semua level dan mata pembelajaran.

Tahapan yang dikemukakan oleh Dick dan Carey (2009) terdiri dari : (1) melakukan identifikasi tujuan pembelajaran;

melakukan analisis intruksional; menganalisis karakteristik siswa dan konteks pembelajaran; (4) merumuskan pembelajaran khusus; (5) mengembangkan instrument penilaian; (6) mengembangkan strategi pembelajaran; (7) mengembangkan dan memilih bahan pembelajaran; (8) merancang dan mengembangkan evaluasi formatif; (9) melakukan revisi terhadap program pembelajaran; (10) merancang dan mengembangkan evaluasi sumatif.

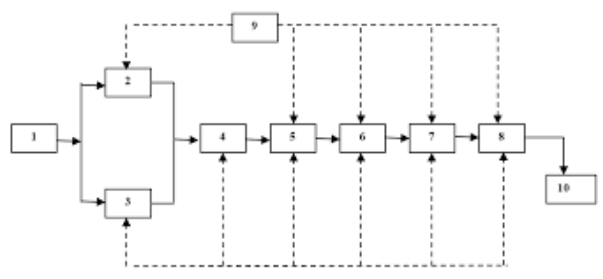

Bagan 3 Model Desain Dick and Carey

\section{HAKEKAT MATA PELAJARAN SIMU- LASI DAN KOMUNIKASI DIGITAL (SIMKOMDIG) KELAS X SMK.}

Simulasi dan Komunikasi Digital (SIMKOMDIG) merupakan salah satu mata pelajaran di SMK yang membekali para siswa agar dapat mengomunikasikan ide pemikiran atau konsep melalui media digital. Menurut 
Rinaldi Munir (2011:10), Para ahli bahasa menemukan kata algorism berasal dari nama cendikiawan muslim yang terkenal yaitu $\mathrm{Abu}$ Ja'far Muhammad Ibnu Musa Al-Khuwarijmi (Al-Khuwarijmi dibaca oleh orang Barat menjadi algorism) dalam bukunya yang berjudul Kitab Aljabar Wal-muqabala, yang artinya "Buku Pemugaran dan Pengurangan" (The book of restoration and reduction). Dari judul buku itu kita memperoleh kata "aljabar" (algebra). Perubahan dari kata algorism menjadi algorithm muncul karena kata algorism sering dikelirukan dengan arithmetic sehingga akhiran -sm berubah menjadi -thm. Mata pelajaran SIMKOMDIG menurut (Suyanto, 2005) dalam buku "Multimedia Alat untuk Meningkatkan Keunggulan Bersaing" dikatakan bahwa multimedia adalah kombinasi dari paling sedikit dua media input atau output dari data, media ini dapat audio (suara, musik), animasi, video, teks, grafik dan gambar. Jadi dapat peneliti simpulkan bahwa multimedia adalah gabungan dari teks, grafik, animasi, audio, dan video yang bertujuan untuk menyampaikan informasi melalui komputer atau media elektronik lainnya.

\section{METODE PENELITIAN}

Penelitian ini dilakukan di SMK Guna Jaya yang berlokasi di Jalan Parit Tuan Brak, Desa Kotabaru Reteh, Kecamatan Keritang, Kabupaten Indragiri Hilir, Riau. Dilaksanakan pada bulan September 2020 sd April 2021.

Penelitian ini menggunakan metode $R e$ search and Development (R\&D). Sugiyono (2009: 407) menyatakan bahwa metode penelitian dan pengembangan adalah metode penelitian yang digunakan untuk menghasilkan produk tertentu, dan menguji keektifan produk tersebut. Untuk dapat menghasilkan produk tertentu digunakan penelitian yang bersifat analisis kebutuhan dengan metode survey. Selanjutnya untuk menguji keefektifan produk tersebut menguji keektifan produk tersebut dilakukan eksperimen sederhana dengan metode one group pre and post-test design. Borg and Gall seperti dikutip oleh Sugiyono (2009:11) menyatakan bahwa untuk penelitian analisis kebutuhan sehingga mampu dihasilkan produk yang bersifat hipotetik sering digunakan metode penelitian dasar (basic research). Setelah produk teruji, maka dapat diaplikasikan. Proses pengujian produk dengan eksperimen tersebut dinamakan penelitian terapan (applied research). Penelitian dan pengembangan bertujuan untuk menemukan, mengembangkan dan memvalidasi suatu produk.

Dalam bidang pendidikan, produk-produk yang dihasilkan melalui penelitian R\&D diharapkan dapat meningkatkan produktivitas pendidikan, yaitu lulusan yang jumlahnya banyak, berkualitas, dan relevan dengan kebutuhan. Produk-produk pendidikan yang dihasilkan dapat berupa kurikulum yang spesifik untuk keperluan pendidikan tertentu, metode mengajar, media pendidikan, buku ajar, modul, kompetensi tenaga kependidikan, sistem evaluasi, model uji kompetensi, penataan ruang kelas untuk model pembelajar tertentu, model unit produksi, model manajemen, sistem pembinaan pegawai, sistem penggajian dan lain-lain (Sugiyono: 2009). Sukmadinata (2008:190), mengemukakan bahwa penelitian dan pengembangan merupakan pendekatan penelitian untuk 
menghasilkan produk baru atau menyempurnakan produk yang telah ada. Produk yang dihasilkan dapat berbentuk software, ataupun hardware seperti buku, modul, paket, program pembelajaran ataupun alat bantu belajar. Penelitian dan pengembangan berbeda dengan penelitian biasa yang hanya menghasilkan saran-saran bagi perbaikan, penelitian dan pengembangan menghasilkan produk yang langsung bisa digunakan.

Pada penelitian merancang pembelajaran Simulasi Digital Kelas X di SMK Guna Jaya Kabupaten Indragiri Hilir menggunakan mtode R\&D yang akan menghasilkan produk berupa rencana pembelajaran (RPP). Penelitian ini dilaksanakan di SMK Guna Jaya yang berlokasi di Jalan Parit Tuan Brak, Desa Kotabaru Reteh, Kec. Keritang, Kab. Indragiri Hilir, Riau.

\section{HASIL DAN PEMBAHASAN}

Pertama, mengidentifikasi beberapa tujuan pembelajaran pada Kompetensi Dasar (KD) siswa pada materi pokok logika dan algoritma komputer diantaranya:

1) Peserta didik mampu menjelaskan logika dan algoritma komputer dengan penuh rasa ingin tahu.

2) Melalui latihan peserta didik mampu memproses logika dan algoritma komputer secara kreatif.

3) Melalui penggalian informasi peserta didik mampu mengemukakan logika dan algoritma komputer secara mandiri.

4) Melalui praktikum peserta didik dapat menerapkan fungsi perintah (command) secara mandiri.

Kedua, melakukan analisis intruksional untuk menentukan keterampilan dan pengetahuan yang relevan untuk mencapai kompetensi pengetahuan, keterampilan dan sikap. Langkah-lagkah sebagai berikut:

1) Peserta didik dipersilahkan oleh guru untuk mengamati video pembelajaran.

2) Peserta didik berdiskusi tentang konsep ide dalam simulasi digital.

3) Berdasarkan penggalian informasi peserta didik dapat mengidentifikasi penggunaan konsep ide dalam simulasi digital.

Ketiga, menganalisis karakteristik siswa, guru diharapkan dapat mengetahui karakter setiap peserta didik saat didalam kelas maupun diluar kelas. Pengamatan ini ditujukan untuk merencanakan media pembelajaran yang cocok diterapkan kepada siswa.

Keempat, merumuskan pembelajaran khusus;

1) Peserta didik mengali informasi berkaitan dengan konsep ide dalam simulasi digital.

2) Peserta didik berdasarkan hasil bacaannya saling bertanya dalam diskusi berkaitan cara meletakkan konsep ide dalam simulasi digital.

3) Berdasarkan bacaan dan diskusi peserta didik dapat memproses langkah-langkah apa saja yang harus dilakukan dalam penerapan konsep ide dalam simulasi digital.

Kelima, mengembangkan instrument penilaian meliputi Pengetahuan (Kognitif) Keterampilan (Psikomotorik), Afektif (Sikap) dan menambahkan Kepemimpinan (Leadership) termasuk kedalamnya penilian tanggungjawab.

Keenam, mengembangkan strategi pembelajaran yang sudah ada seperti 
1) Strategi Pembelajaran Inkuiri (tanya jawab antara siswa dan guru).

2) Strategi Pembelajaran Kooperatif (kelompok).

3) Strategi Pembelajaran Ekspositori (penyampaian materi secara verbal oleh guru kepada siswa).

4) Strategi Pembelajaran Kontekstual (mengaitkan dengan dunia nyata).

5) Strategi Pembelajaran Peningkatan Kemampuan Berpikir (konsep memanfaatkan pengalaman yang dimiliki para siswa).

6) Strategi Pembelajaran Berbasis Masalah (belajar dari masalah yang dialami).

7) Strategi Pembelajaran Afektif (Sikap).

Ketujuh, merancang dan mengembangkan evaluasi formatif bagi guru saat sedang mengajar dan memberi tugas kepada siswa. Contoh evaluasi adalah siswa mencoba mengaitkan tugas yang diberi dengan kehidupan sehari-hari misalnya dalam menerapkan algoritma di kehidupan sehari-hari.

Kedelapan, guru melakukan penilaian formatif untuk memantau kemajuan belajar siswa selama proses belajar berlangsung. Contoh dalam materi algoritma, guru memberikan suatu masalah yang harus diselesaikan dalam kehidupan sehar-hari sesuai dengan alur algoritma dan menerapkan langkah-langkah sistematis. Misalnya dalam kasus cara membuat mi instan. Guru dapat melihat sejauh mana pemahaman siswa dalam menguraikan langkah-langkah membuat mi instan yang benar sesuai dengan algoritma.

Kesembilan, melakukan revisi terhadap program pembelajaran Simulasi dan Komukasi Digital dengan cara menganalisa kebutuhan siswa. Contoh kebutuhan praktikum dan peralatan pendukung lain seperti software dan modul.

Kesepuluh, merancang dan mengembangkan evaluasi sumatif. Evaluasi secara keseluruhan terkait proses Kegiatan Belajar Mengajar (KBM) untuk siswa dan guru dengan harapan mendapatkan masukan dari berbagai pihak dalam hal ini siswa dan guru agar memperoleh proses belajar yang lebih baik.

\section{KESIMPULAN}

Penerapan model pengembangan Dick dan Carey dalam pengembangan pembelajaran Simulasi dan Komunikasi Digital (SIMKOMDIG) membantu guru menciptakan KBM lebih tersistem, efisien, dan efektif. Guru dapat mengelompokkan kegiatankegiatan yang akan dilaksanakan dalam proses KBM lebih sistematis dan sistemik. Guru dapat memilih strategi pembelajaran yang sesuai untuk peserta didik. Guru dapat memilih bahan pembelajaran yang sesuai dengan kebutuhan siswa dan mengevaluasi keberhasilan belajar siswa yang sesuai dengan tujuan pembelajaran. Dengan demikian diharapkan dapat meningkatkan kualitas pendidikan di SMK Guna Jaya.

\section{REFERENSI}

Aay Hidayah. (2012). Research and Development (RnD) sebagai salah satu model penelitian dalam bidang pendidikan. Jurnal Akademik. Vol. 37 (No. https://www.academia.edu/download/ $\underline{38758800 / 13-21-1-S M . p d f}$

Benny A. Pribadi. (2009). Model Desain Sistem Pembelajaran. Jakarta: Dian Rakyat. 
Crismawati. (2021). Pengembangan Modul Pembelajaran Simulasi Digital Kelas X TKJ di SMKN 5. Jurnal Media TIK. Vol. 4 (No. 2). https://ojs.unm.ac.id/mediaTIK/articl e/download/21364/11126.

Dick, Walter and Carey, Lou. (2009). The Systematic Design of Instruction. New Jersey: Pearson.

Hariyanto, Bambang. (2007). Esensi-esensi bahasa pemrograman Java. Informatika. Bandung.

Sugiyono. (2009). Metode Penelitian Pendidikan Pendekatan Kuantitatif, Kualitatif, dan R \& D. Bandung: Alfabeta
Suradika, A., Winata, W., Wicaksono, D., Hadi, M. S., \& Rifqiyati. (2020). The Influence of Instructional Materials and Educational Background on the Learning Outcomes of Islamic Education. Solid State Technology, 63(6), 1027-1043. http://solidstatetechnology.us/index.p hp/JSST/article/view/2185

Wisnu. (2016). Model Pembelajaran Dick dan Carey dalam pembelajaran Bahasa dan Sastra Indonesia. Kajian Linguistik dan Sastra. Vol. 1 (No. 2). http://journals.ums.ac.id/index.php/K LS/article/viewFile/3631/2307 